\title{
Characterization and control of a pneumatic microactuator with an integrated inductive position sensor
}

\author{
M. De Volder ${ }^{\mathrm{a}, *}$, J. Coosemans ${ }^{\mathrm{b}}$, R. Puers $^{\mathrm{b}}$, D. Reynaerts ${ }^{\mathrm{a}}$ \\ ${ }^{a}$ Department of Mechanical Engineering, Katholieke Universiteit Leuven, Celestijnenlaan 300B, Leuven, Belgium \\ ${ }^{\mathrm{b}}$ Department of Electrical Engineering, Katholieke Universiteit Leuven, Kasteelpark Arenberg 10, Leuven, Belgium
}

Received 23 May 2007; received in revised form 13 July 2007; accepted 17 July 2007

Available online 22 July 2007

\begin{abstract}
As the intelligence and the functionality of microrobots increase, there is a growing need to incorporate sensors into these robots. In order to limit the outer dimensions of these microsystems, this research investigates sensors that can be integrated efficiently into microactuators. Here, a pneumatic piston-cylinder microactuator with an integrated inductive position sensor was developed. The main advantage of pneumatic actuators is their high force and power density at microscale. The outside diameter of the actuator is $1.3 \mathrm{~mm}$ and the length is $15 \mathrm{~mm}$. The stroke of the actuator is $12 \mathrm{~mm}$, and the actuation force is $1 \mathrm{~N}$ at a supply pressure of $1.5 \mathrm{MPa}$. The position sensor consists of two coils wound around the cylinder of the actuator. The measurement principle is based on the change in coupling factor between the coils as the piston moves in the actuator. The sensor is extremely small since one layer of $25 \mu \mathrm{m}$ copper wire is sufficient to achieve an accuracy of $10 \mu \mathrm{m}$ over the total stroke. Position tests with a PI controller and a sliding mode controller showed that the actuator is able to position with an accuracy up to $30 \mu \mathrm{m}$. Such positioning systems offer great opportunities for all devices that need to control a large number of degrees of freedom in a restricted volume.
\end{abstract}

(C) 2007 Elsevier B.V. All rights reserved.

Keywords: Fluidic microactuator; Inductive micro-position-sensor; Mechatronic microsystem; Integrated actuator-sensors system; Microrobotics; Sliding mode control; PI control

\section{Introduction}

New microrobotic applications require compact actuators with a high force and power density. Up to now, little research has been performed on the development of pneumatic or hydraulic microactuators, despite the fact that these actuators offer great prospects for achieving high force and power densities [1-5]. This paper investigates the miniaturization of the classic pistoncylinder actuators that are often applied in large-scale systems. The general layout of such actuators is illustrated in Fig. 1. This is a typical pneumatic double acting actuator, which means that the actuator is able to generate both pulling and pushing forces depending whether the pressure is applied to port 1 or 2 , respectively.

In many robotic applications, the position of the actuator needs to be controllable. In order to achieve this in a compact

\footnotetext{
* Corresponding author. Tel.: +32 16322 526; fax: +32 16322987.

E-mail address: Michael.devolder@mech.kuleuven.be (M. De Volder).
}

way, methods to incorporate a position sensor into the actuator have been investigated. This paper presents an inductive position sensor that consists of a thin coil wound around the actuator. The measurement principle is based on the change in coupling factor between the coils as the piston rod moves in the cylinder. The final objective of this research is to develop a miniature sensor-actuator system with an actuation force of $1 \mathrm{~N}$, a stroke of $10 \mathrm{~mm}$, a cross-section of $1 \mathrm{~mm}^{2}$ and a length below $15 \mathrm{~mm}$. The integrated position sensor should allow a positioning accuracy better than $50 \mu \mathrm{m}$. In what follows, the design and fabrication of the actuator and the sensor will be discussed and the performance of the total system, including position control, will be evaluated. Compact pneumatic actuators with integrated position sensors have also been proposed by Wakimoto et al. [6], Zhu and Book [7], and Peirs [8], nevertheless, the diameter of these actuators is more than three times larger, and the reported position accuracy is an order of magnitude lower than that of the system presented in this paper. 


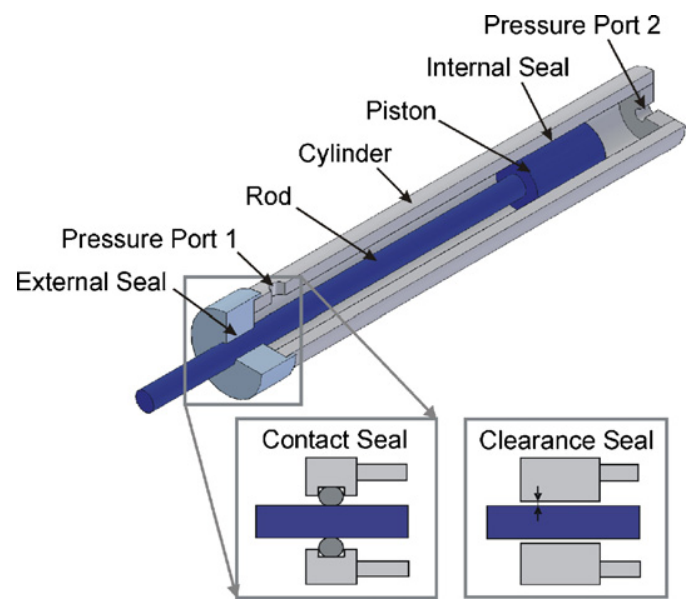

Fig. 1. General layout of the fluidic actuators investigated in this paper. The lower part of this figure shows two seal configurations that have been considered in this research.

\section{The fluidic microactuator}

Actuators similar to the ones presented in this paper, but without position sensor have been described in an earlier publication [1]. Therefore, this publication will discuss the actuators briefly, and then focus on the position sensor and the control system. The main technological barrier in the development of pneumatic actuators is the fabrication of powerful microseals with low leakage. For instance O-rings, or other contact seals (see Fig. 1), are inappropriate for miniaturization since small production errors on this type of seals result in high leakage or friction $[1-3,8]$. Therefore, new seal technologies for pneumatic microactuators must be investigated. The seal implemented in this paper is based on the fact that the leakage between a rod and an orifice is very low if a small clearance is realized between both components, as illustrated in Fig. 1 [1]. These seals will be referred to as clearance seals. The main difference with rubber O-rings is that the length over which the flow is restricted is much longer in the case of a clearance seal. Therefore, it is not needed to have a direct contact between the piston rod and orifice to limit the leakage.

A first advantage of clearance seals is that the friction generated by these seals is lower than that of for instance rubber O-rings which are pressed on the piston rod. A second important advantage of clearance seals is that a trade-off can be made between the fabrication accuracy and leakage of the actuator. For instance, in several medical applications a certain amount of leakage is not detrimental if the actuator is driven by physiolog-

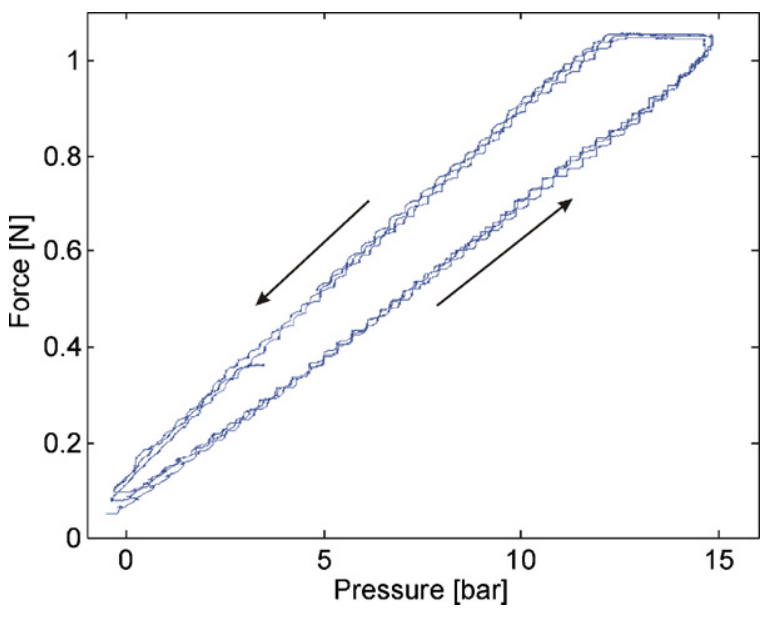

Fig. 3. Actuation force of the actuator as a function of the applied pressure for three pressure cycles between 0 and $1.5 \mathrm{MPa}$.

ical water $[8,9]$. Consequently, clearances of a few micrometers between the piston and the orifice are acceptable. Nevertheless, the leakage can virtually be reduced to zero if required by the application, but in that case, tolerances in the range of $1 \mu \mathrm{m}$ or less are needed on the seal and the piston. Especially achieving a good roundness and cylindricity revealed to be challenging. The seals used in this research are fabricated by Micro Electro Discharge Machining ( $\mu E D M)$, Deep Reactive Ion Etching (DRIE), micromilling or SU8 technology (see Fig. 2) [1]. The outside diameter of the actuator is $1.3 \mathrm{~mm}$, the length is about $15 \mathrm{~mm}$, and the stroke of the actuator is $12 \mathrm{~mm}$. The piston rod has a diameter of $0.5 \mathrm{~mm}$, and the piston itself has a diameter of $1 \mathrm{~mm}$. The clearance between the piston rod and the seal orifice is about $5 \mu \mathrm{m}$ in average. The actuator can typically achieve actuation forces of about $1 \mathrm{~N}$ at a supply pressure of $1.5 \mathrm{MPa}$ as illustrated in Fig. 3. This figure shows the actuation force as a function of the overpressure applied on port 2 (see Fig. 1). These relatively high pressures are used in order to achieve high force densities. More information these actuators can be found in [1].

\section{The inductive position sensor}

This research focused on the development of inductive position sensors. Inductive position sensors are excellent for measuring linear displacements $[10,11]$, and they are especially interesting for integration in pneumatic actuators since they combine a high resolution with a long sensing stroke and allow

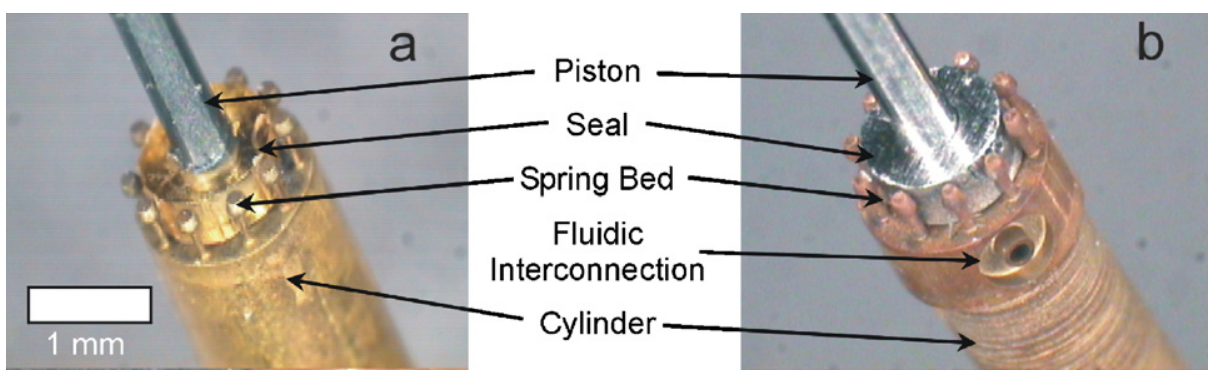

Fig. 2. Prototype microactuators sealed by clearance seals. Left: a clearance seal made of SU8. Right: a clearance seal fabricated by $\mu$ EDM in stainless steel. 


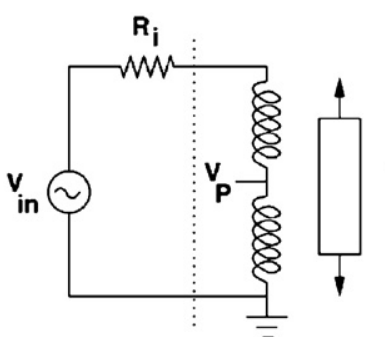

(a)

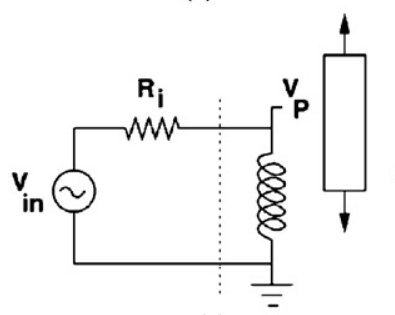

(c)

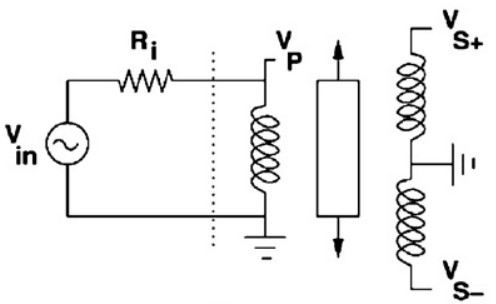

(b)

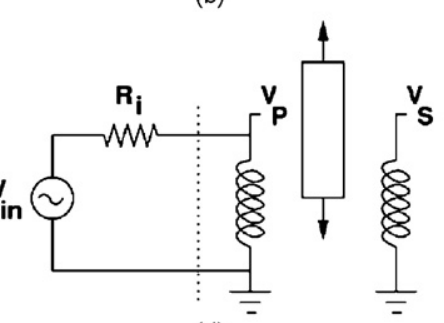

(d)
Fig. 4. Overview of inductive displacement sensors: DVRT (a) LVDT, (b) and their single-ended counterparts (c, d).

contact-less measurements. The DVRT (differential variable reluctance transformer or half-bridge LVDT; Fig. 4a) and the LVDT (linear variable differential transformer; Fig. 4b) offer excellent linearity and therefore are the most frequently used linear displacement sensors. However, for the position sensing in a microactuator, it is an important drawback that both use a series connection of two coils (series opposed configuration in case of the LVDT). This implies that the stroke is limited to less than half the length of the sensor, resulting in an unacceptably low stroke-to-length ratio of the actuator. Therefore, the singleended counterparts of the DVRT and the LVDT, illustrated in Fig. $4 \mathrm{c}$ and $\mathrm{d}$, were investigated in this research.

The variable reluctance transformer (Fig. 4c) is based on the change of the coil inductance with the position of the core. Its application to sense the rod position in a large-scale hydraulic cylinder has been described in [12]. This paper investigates the feasibility of these sensors in microactuators. The change in inductance is the net result of two counteracting effects:

- When a high permeability rod is inserted in the coil, the magnetic reluctance decreases, resulting in a higher magnetic flux, and thus in an increase of the coil inductance.

- When a conductive rod is inserted in a coil that is driven with an AC current, eddy currents will circulate in the opposite direction, reducing the magnetic flux in the coil and thereby its inductance.

Here, a high permeability steel rod is used, so the first effect is dominant in the frequency range of interest. The sensor should be very small, and therefore thin coil wires and few windings are used. Consequently, the inductance values are small and the coil impedance is dominated by the dc resistive part of the wires. As a result, the effect of the moving piston on the impedance of the primary coil is insignificant, and the primary voltage $V_{\mathrm{p}}$ is nearly constant when the input voltage $V_{\text {in }}$ is kept constant. Hence the configuration of Fig. 4c shows a low sensitivity.
The sensitivity can be increased by an order of magnitude by using the setup in Fig. 4d, where two coils are evenly spread over the actuator length. Suppose a high permeability core is inserted into the cylinder. The magnetic coupling factor between both coils will increase nearly linear with the insertion depth of the core. This effect adds up with the increase in the primary coil impedance, described above. Inserting a core increases the primary coil voltage $V_{\mathrm{p}}$ due to the resistive division with the source impedance $R_{\mathrm{i}}$, and simultaneously increases the coupling factor with the secondary coil, increasing the secondary coil voltage $V_{\mathrm{s}}$ even faster. The latter effect is dominant and is studied into more detail. The two coils around the actuator act as a loosely coupled transformer. A current $i_{\mathrm{p}}$ in the primary coil induces a voltage $V_{\mathrm{s}}$ in the secondary coil:

$V_{\mathrm{s}}=-M \frac{\mathrm{d} i_{\mathrm{p}}(t)}{\mathrm{d} t}$

where $M$ is the mutual inductance between both coils. If the cross-sectional area of the ferromagnetic rod is less than the area of the coil, the mutual inductance is given by $[9,10]$ :

$M=\mathrm{A} \mu_{0}\left[1+\left(\frac{A_{\text {rod }}}{A}\right)\left(\mu_{\text {rod }}-1\right)\right] \frac{N_{1} N_{2}}{l}$

where $\mu_{0}$ is the permeability of vacuum, $\mu_{\text {rod }}$ the effective permeability of the ferromagnetic rod. $\mu_{\text {rod }}$ can be found in [13]. $A$ is the cross-section area of the coils, $N_{1}$ and $N_{2}$ are the number of turns of the primary and secondary coils and $l$ is the length of the coil, $A_{\text {rod }}$ is the cross-sectional area of the ferromagnetic rod. From (1) and (2) it can be seen that the induced voltage $V_{\mathrm{s}}$ is then increased by a factor $\mu_{\mathrm{e}}+1$ over the value for the same coil in free space. Where

$\mu_{\mathrm{e}}=\left(\frac{A_{\text {rod }}}{A}\right)\left(\mu_{\text {rod }}-1\right)$

If the ferromagnetic core is only partially inserted in the coil, then $\mu_{\mathrm{e}}$ is proportional to the insertion depth [14], and therefore, the output voltage of the sensor is also proportional to the insertion depth.

As described above, the position sensor consists of two coils that are evenly spread over the actuator length. To simplify the winding of these two coils, a single wire consisting of two copper strands is used. This method guarantees an equal distribution of the primary and secondary coil. To minimize the dimensions of the sensor, only one layer of wire is used and the diameter of each copper strand is limited to $25 \mu \mathrm{m}$. This means that the presented sensor is extremely small: it only adds $50 \mu \mathrm{m}$ to the $1.3 \mathrm{~mm}$ diameter of the actuator. Fig. 5 shows the actuator of Fig. 2b after winding the coil of the position sensor.

To investigate the influence of the material properties, cylinders made out of aluminium, copper and brass were tested. Also different piston types were studied. Two steel pistons $(\emptyset 1 \mathrm{~mm}$, and $\varnothing 0.5 \mathrm{~mm})$ and two ferrite pistons $(\varnothing 1 \mathrm{~mm}$, length $10 \mathrm{~mm}$ and $\varnothing 0.75 \mathrm{~mm}$, length $7.5 \mathrm{~mm}$ ) were used. The ferrite pistons are made of 78 Material from Fair-Rite Products Corp. This MnZn ferrite has a small loss tangent for frequencies up to $200 \mathrm{kHz}$, 


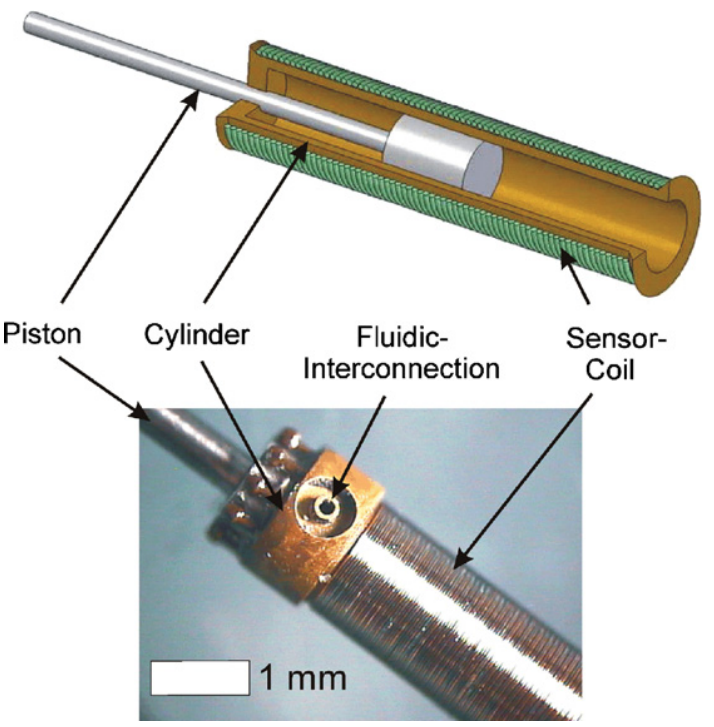

Fig. 5. Microactuator from Fig. $2 \mathrm{~b}$ after winding the coil of the position sensor.

and an initial permeability $\mu_{\mathrm{i}}$ of 2300 . Given the rod dimensions, it can be found that the rod permeability $\mu_{\text {rod }}$ for both ferrite pistons equals 48 .

In a first measurement the optimal excitation frequency was determined. The primary coil was connected to the output of a network analyser (HP3577) and the voltages on the primary coil $\left(V_{\mathrm{p}}\right)$ and secondary coil $\left(V_{\mathrm{s}}\right)$ were measured. This was done for an aluminium cylinder, both without core, and with a $1 \mathrm{~cm}$ long ferrite core fully inserted. The measurements are shown in Fig. 6a and $b$.

It can be seen that the voltage on the secondary coil is more than an order of magnitude more sensitive to the presence of the core than the voltage on the primary coil. As discussed earlier on, the effect of the moving piston on the impedance of the primary coil is indeed very small. Consequently a sensor based on the change of inductance with the core position, as in Fig. $4 \mathrm{c}$, is not feasible. This is also illustrated by Table 1, which displays the resistance, inductance, impedance and quality factor of the primary coil, both with and without the ferrite core, measured at $10 \mathrm{kHz}$ with an LRC meter (HP4248A). The effect of the rod permeability on the sensitivity of the sensor is shown in Fig. 6c. The frequency response of a sensor with an aluminium cylinder is measured with ferrite cores $(\emptyset 1 \mathrm{~mm}$ and $\emptyset 0.75 \mathrm{~mm})$, a steel core $(\emptyset 1 \mathrm{~mm})$ and without core.

For low frequencies, the induced voltage is proportional to the frequency, according to Eq. (1) $\left(i_{\mathrm{p}}\right.$ is independent of the frequency $f$ since $R_{\mathrm{S}} \gg 2 \pi f L_{\mathrm{S}}$ ). Note that the voltage gain due to

Table 1

Properties of the primary coil, wound on an aluminium cylinder

\begin{tabular}{lll}
\hline & Without core & With ferrite $\operatorname{rod}(\emptyset 1 \mathrm{~mm})$ \\
\hline$R_{\mathrm{S}}$ & $29.33 \Omega$ & $30.72 \Omega$ \\
$L_{\mathrm{S}}$ & $4.057 \mu \mathrm{H}$ & $7.054 \mu \mathrm{H}$ \\
$Z$ & $29.33 \Omega$ & $30.72 \Omega$ \\
$Q$ & 0.009 & 0.014 \\
\hline
\end{tabular}

Measurements performed at $10 \mathrm{kHz}$.
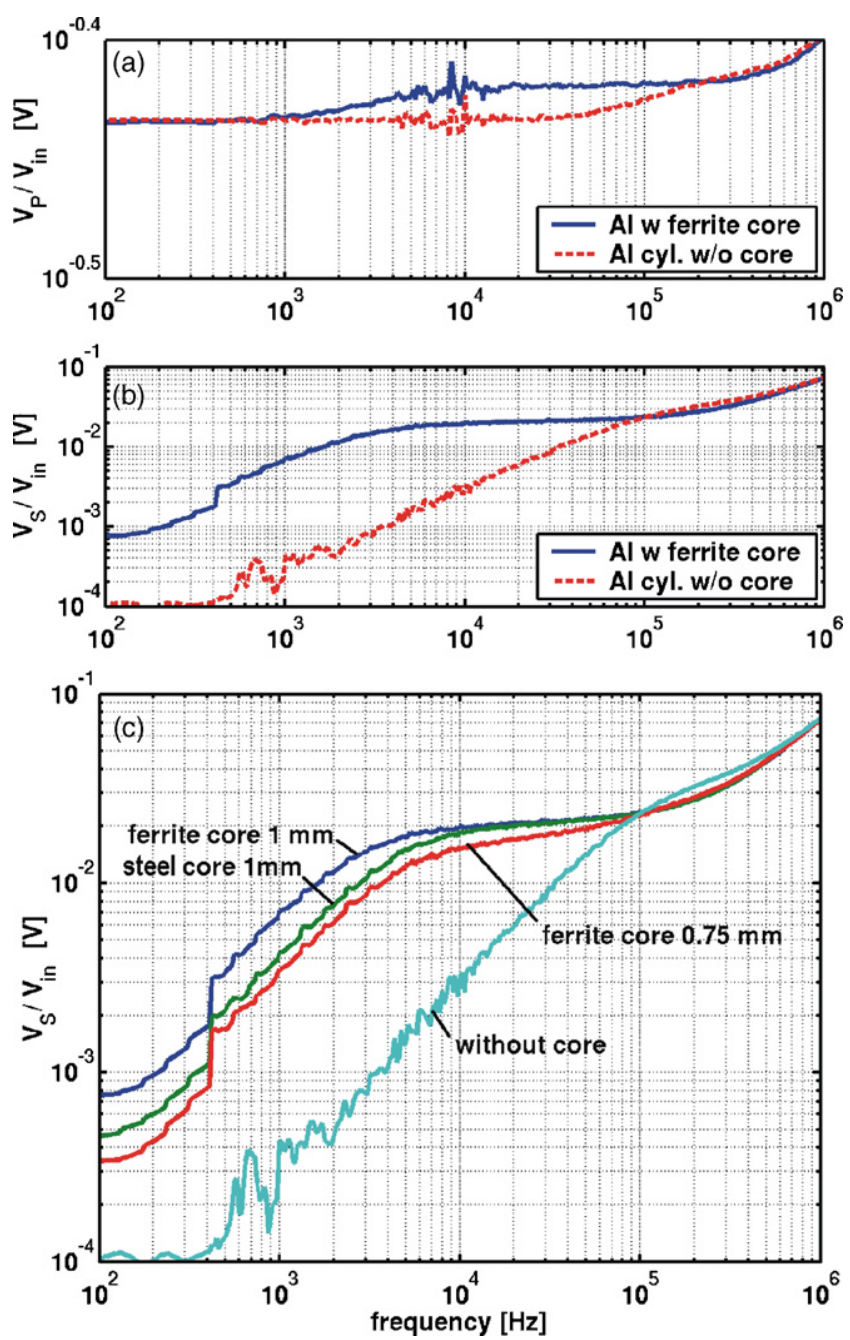

Fig. 6. Sensitivity of the sensor as a function of the excitation frequency. (a) Voltage on the primary coil. (b) Voltage on the secondary coil. (c) Effect of the core permeability on the sensitivity of the sensor.

the presence of the ferrite cores is in good agreement with Eq. (3). This equation predicts the voltage gain $\mu_{\mathrm{e}}+1$ for the ferrite cores to be 28.8 for the $\emptyset 1 \mathrm{~mm}$ core and 16.6 for the $\emptyset 0.75 \mathrm{~mm}$ core. From the measurements in Fig. 6, the induced voltage (at $2 \mathrm{kHz}$ ) has increased by a factor of 26 and 14 respectively. For high frequencies $(>200 \mathrm{kHz})$, the losses in the ferromagnetic core increase, the material permeability decreases, and consequently, all curves coincide.

For intermediate frequencies, in presence of a ferromagnetic core, there is a cut-off frequency in the induced voltage at about $5 \mathrm{kHz}$. This is caused by induced eddy currents circulating in the metallic cylinder. These eddy currents increase with the frequency, and apparently, for the aluminium cylinder, they become dominating at $5 \mathrm{kHz}$. In higher resistive materials, the eddy currents are smaller and the cut-off frequency is higher. This is illustrated by the left hand side of Fig. 7, which shows the frequency response for sensors with different cylinder materials, with and without a ferrite core $(\emptyset 1 \mathrm{~mm})$. For low frequencies, the cylinder material has no influence on the sensor, but for intermediate frequencies, the sensor with the brass cylinder will 


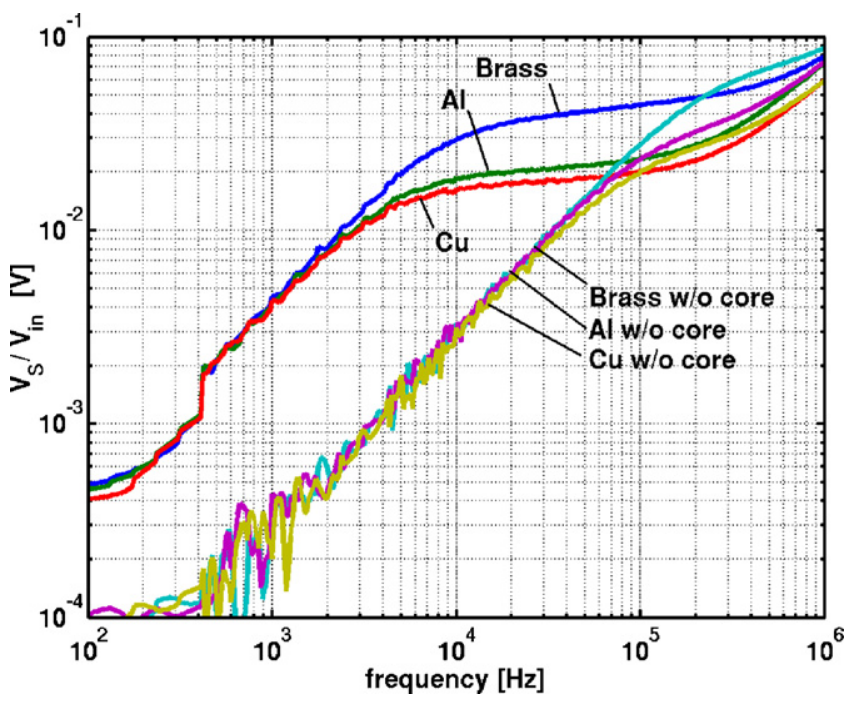

Fig. 7. Influence of the cylinder material on the sensitivity of the sensor.

show the highest sensitivity. Brass has a higher resistivity than aluminium and copper, what is directly reflected in the cut-off frequency.

The set-up to measure the position of the piston in the actuator is built around the AD698 from Analog Devices, as shown in Fig. 8. This universal LVDT signal conditioner contains an internal oscillator to drive the LVDT primary. Two synchronous demodulation channels are used to detect primary and secondary amplitude. The AD698 divides the output of the secondary by the amplitude of the primary, yielding an output that is directly proportional to the coupling factor between the primary and secondary coils. This eliminates scale factor errors due to drift in the amplitude of the primary drive, improving temperature performance and stability.

From Fig. 7, the excitation frequency is set to $10 \mathrm{kHz}$, as a trade-off between sensitivity and signal magnitudes. As the AD698 is intended for large-scale sensors, the excitation output voltage ranges from 2.1 to $24 \mathrm{~V}_{\mathrm{RMS}}$, which cannot be applied to our microactuator. A sine wave of $5 \mathrm{~V}$, would dissipate $0.4 \mathrm{~W}$ in a $30 \Omega$ resistance, and heat up the system. Through the thermal sensitivity, this would lead to a large settling time of the output, and it might introduce hysteresis as well. To avoid these problems, a resistive divider is used to place a differential signal of $500 \mathrm{mV}_{\mathrm{p}}$ across the primary coil. The signal on the secondary coil is amplified by a factor 15 to meet the input requirements of the AD698. The secondary coil is prone to $50 \mathrm{~Hz}$ interference as well as HF spikes from the environment. These noise signals appear mainly in common mode, as they are picked up by the connection wires to the sensor. To reduce this interference, an amplifier topology was chosen that rejects the common mode signals, and the common mode impedance to ground was lowered by two RC filters, with a cut off frequency of $15 \mathrm{kHz}$. Another RC filter rejects the high frequency differential noise. The filters after the demodulators in the AD698 were designed for a sensor bandwidth of $50 \mathrm{~Hz}$.

To measure the performance of the sensors, it is necessary to have a positioning system that can move the piston to an exactly known position inside the cylinder. In our test set-up, this is achieved by fixing the cylinder on a precision XY table. The piston was extended and retracted 5 times, while the output voltage was measured at incremental steps of $0.5 \mathrm{~mm}$. The position measurements were performed with steel pistons since this material

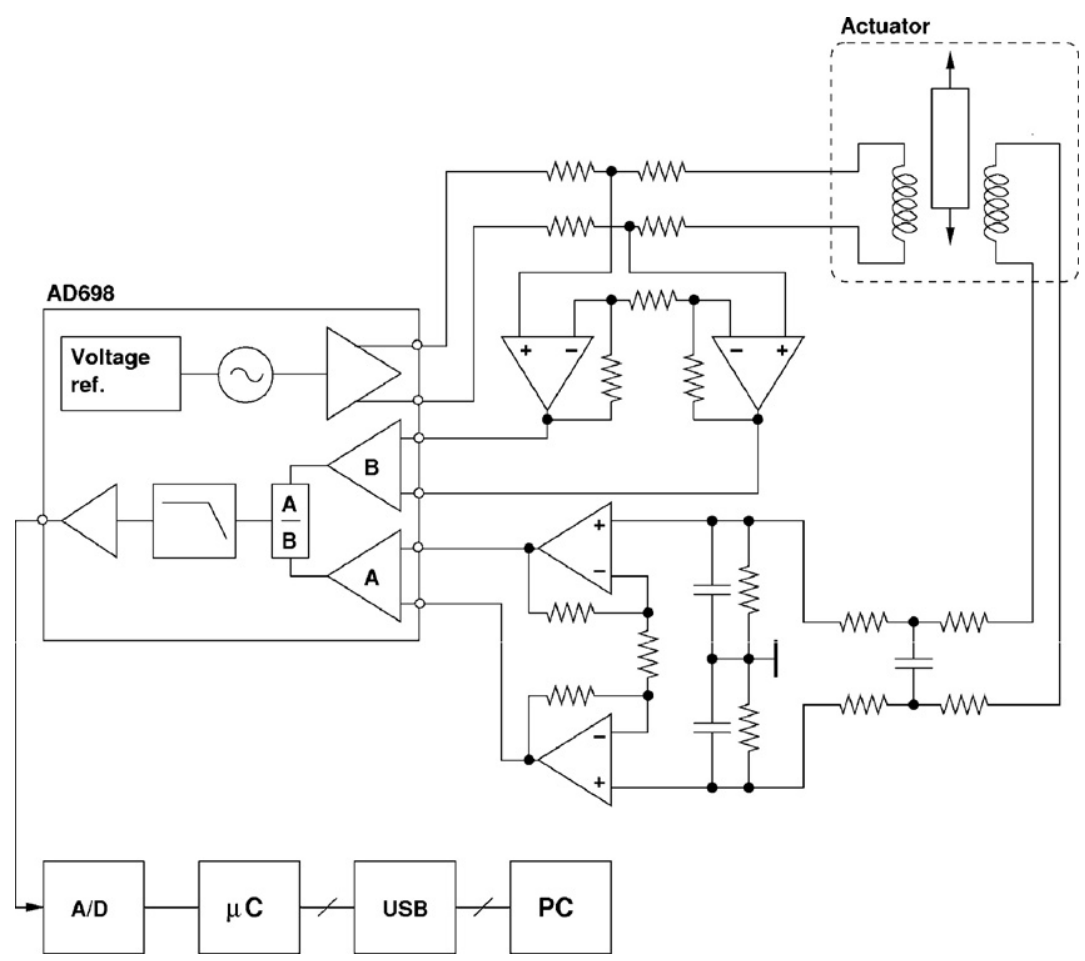

Fig. 8. Set-up used for measuring the output voltage as a function of the core insertion into the cylinder. 

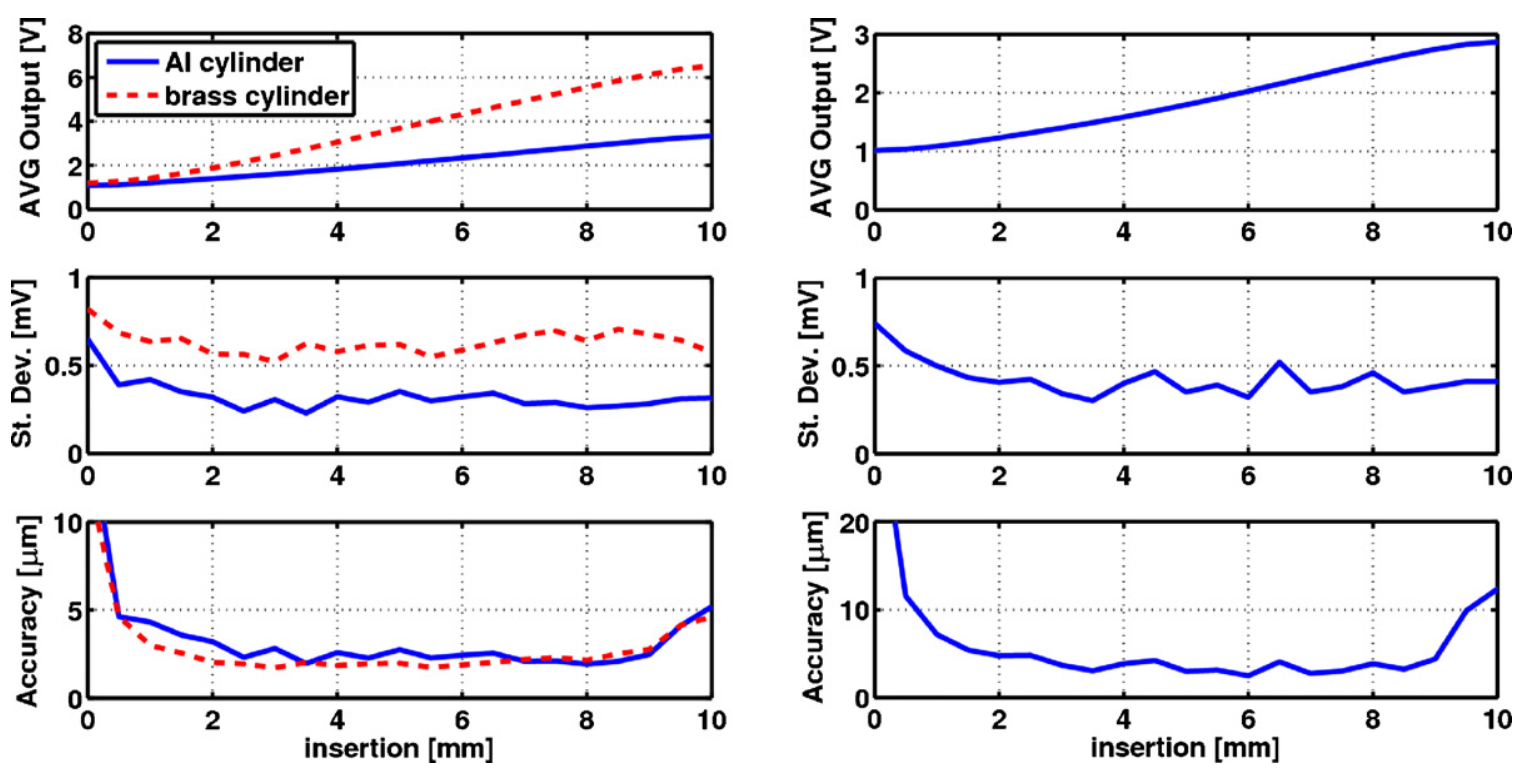

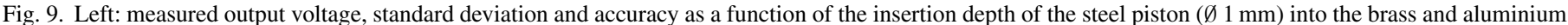
cylinders. Right: measured output as a function of the steel piston $(\varnothing 0.5 \mathrm{~mm})$ insertion depth into the aluminium cylinder.

offers the highest flexibility for integration in the production process of the actuator aimed at. Furthermore, Fig. 6 reveals that at $10 \mathrm{kHz}$ the sensitivity for steel pistons is comparable to that of ferrite pistons.

Fig. 9 left, shows the measurement results for a brass and an aluminium cylinder with a $1 \mathrm{~mm}$ diameter steel piston. The sensitivity $s$ of the sensor can be calculated for each insertion as the first derivative of the output voltage with respect to the insertion. The average sensitivity (without amplification) equals $5.33 \mathrm{mV} / \mathrm{V} / \mathrm{mm}$ for the brass cylinder and $2.25 \mathrm{mV} / \mathrm{V} / \mathrm{mm}$ for the aluminium cylinder, comparable to typical values for LVDT sensitivity. The standard deviation $\sigma$ on the output voltage is also shown in Fig. 9.

The bi-directional accuracy is within $\pm 5 \mu \mathrm{m}$ for each insertion starting from $0.5 \mathrm{~mm}$. To find out if the position sensor is also applicable to the double acting actuators sketched in Fig. 5, the above-described measurements were repeated for a steel piston $\emptyset 0.5 \mathrm{~mm}$ in a cylinder with a bore of $1 \mathrm{~mm}$. The results are shown in Fig. 9, right. The average sensitivity has diminished from 2.25 to $1.85 \mathrm{mV} / \mathrm{V} / \mathrm{mm}$ and since the standard deviation is about the same as before, the precision has decreased to $\pm 10 \mu \mathrm{m}$ over $85 \%$ of the total length of the actuator. The end effect near zero insertion is however no problem since the piston is always inserted at least one $\mathrm{mm}$ in the actuator. If desired, the sensitivity and the precision of the sensors can be improved by adding one or more layers to the coil winding, at the cost of increasing the outer diameter. A drawback of the position sensor is its sensitivity to the environmental temperature. Experiments to quantify this phenomenon are performed by heating the system with a heat gun. These experiments showed that the output signal changes up to $15 \mu \mathrm{m}$ for a temperature change of about $15^{\circ} \mathrm{C}$. Since all the experiments discussed further on are performed in temperature controlled room at $20^{\circ} \mathrm{C}$, this effect will not be considered in what follows.

\section{Position control}

The aim of the control system described in this section is to investigate the feasibility of accurate positioning with the above described actuator-sensor system. Since small piston-cylinder actuators typically show a lot of friction, a feed-back position control system was developed.

A first important issue when investigating the positioning capabilities of the actuator is its mounting in the test set-up. It is important to avoid a hyperstatic clamping of the actuator since this can lead to a high friction. At the same time, it is desirable to be able to remove the actuator from its clamping. In this case, these requirements are achieved by clamping the actuator in a snap fit. This system is illustrated in Fig. 10: short clamping-rods

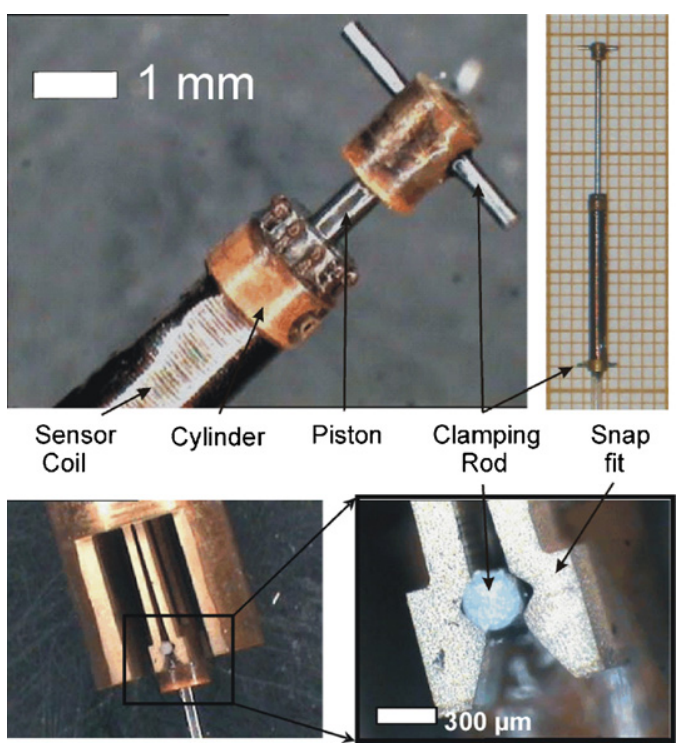

Fig. 10. Illustration of the snap-fit system used to clamp the actuator. 


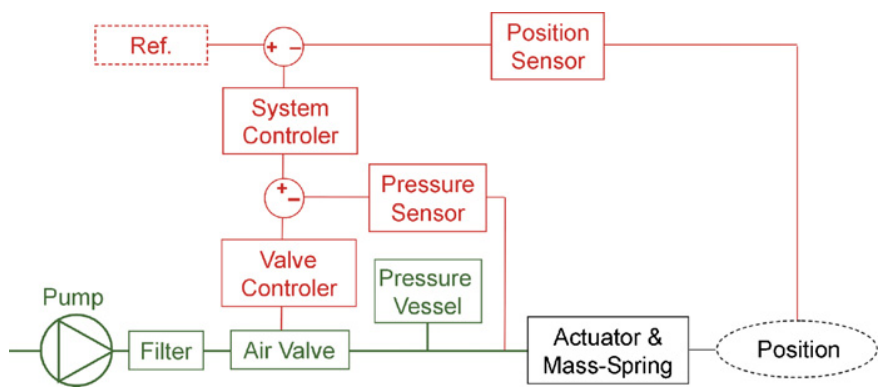

Fig. 11. Overview of the control scheme and the experimental setup.

which can be clamped in a snap-fit are mounted on the actuator. As can be seen in Fig. 10, these snap-fits are compact, and they can be integrated monolithically into the system that needs to be actuated, which facilitates the assembly. Measurements showed that the hysteresis introduced by the snap-fits and the position sensor is less than $8 \mu \mathrm{m}$. Alternatively, more straightforward hole-pin clampings can be used, these are however permanent.

A general overview of the test setup used in this research is given in Fig. 11. It consists of the following elements:

- Pump: a standard pressurized air supply delivering 1.6 MPa was used to drive the actuator. Similar tests can be performed using a pressurized liquid, as described in an earlier publication [1].

- Filters: the air is filtered in two steps to $1 \mu \mathrm{m}$ in order to prevent particles from jamming the actuator.

- Valves: a commercial pneumatic proportional valve was used to control the actuator (Festo MPYE-5). It is possible to control microactuators using this commercial valve as will be shown by measurements later on.

- Pressure vessels: a pressure vessel was added to the system. This pressure vessel reduces dynamic response, but has the advantage that it allows to control the pressure more accurately and smoothes the pressure output of the valve.

- Pressure sensors: a silicon based pressure sensor was used to monitor the pressure applied on the actuator (Druck PMP 1400).

- Translational stage: the actuator was clamped with a snap fit in the linear translational stage shown in Fig. 12. It consists of a leaf-spring construction that can be deflected by the actuator (see Fig. 12). The leaf-springs are used in order not to introduce friction in the system. The stiffness of the stage is $0.1 \mathrm{~N} / \mathrm{mm}$.

- Laser interferometer: the position sensor was calibrated using a laser interferometer (Renishaw ML10). This device is also used as an external reference to check the position accuracy of the sensor-actuator system.

- Controller: finally, a controller was developed to drive the actuator. For this purpose, a PI controller was designed with anti wind-up and saturation on the integration in order to avoid overshoots and stick-slip cycling [15]. The controller parameters are determined by an ad hoc method that is often used for PI controllers: first the proportional gain is increased until the system reaches a nervous, oscillating state. Then the integral component is increased until the oscillation stops. The

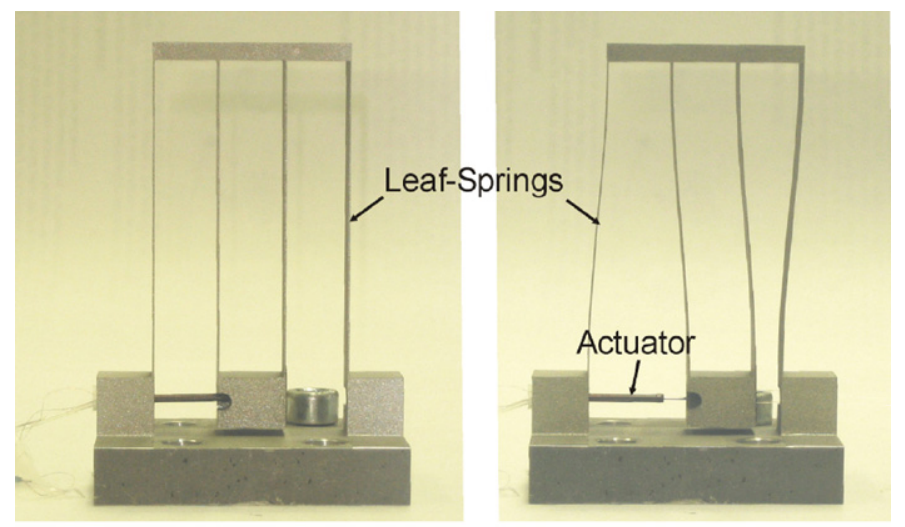

(a) Low Pressure

(b) High Pressure

Fig. 12. The translational stage used during the positioning tests.

control of the actuator is challenging due to the relatively high coulomb friction force in piston-cylinder microactuators. This was partially remediated by adding a minute amount of lubrication to the piston and by implementing more advanced sliding mode controllers.

Fig. 13 shows staircase positioning tests in which the actuator makes steps of $250 \mu \mathrm{m}$, using the integrated inductive position sensor. The position is also measured by a laser interferometer as external reference in order to check the accuracy of the

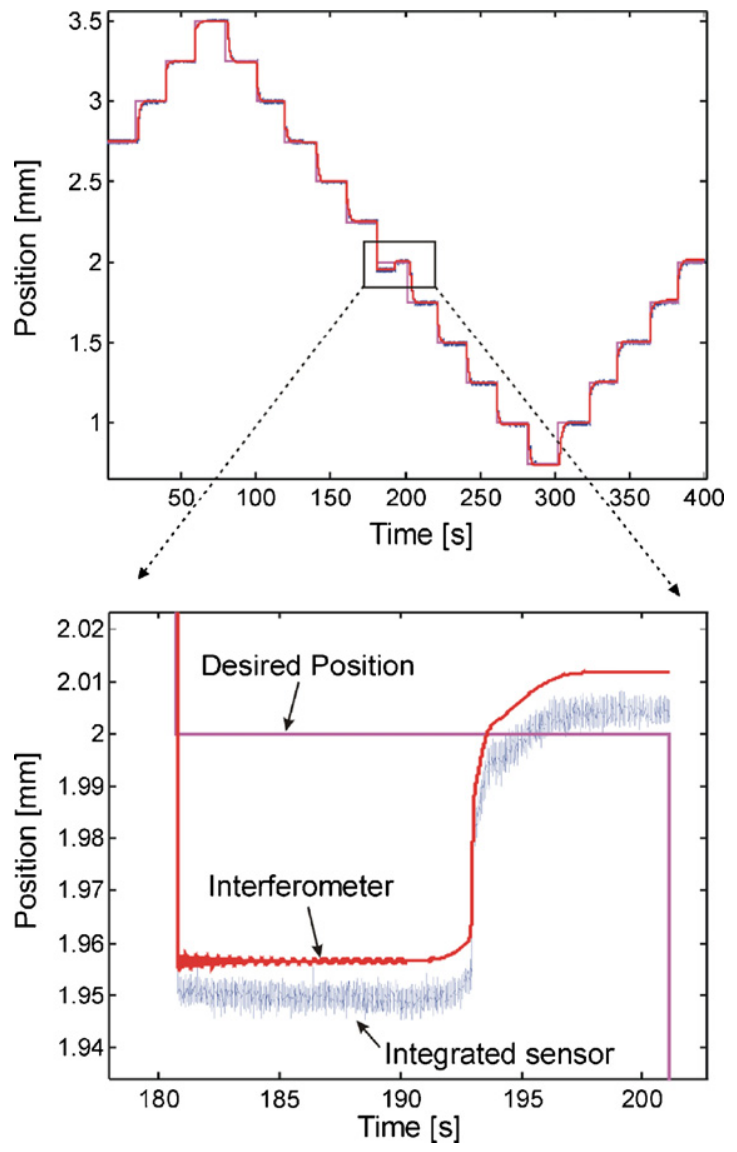

Fig. 13. Measurement of the actuation accuracy with an interferometer as external reference. 


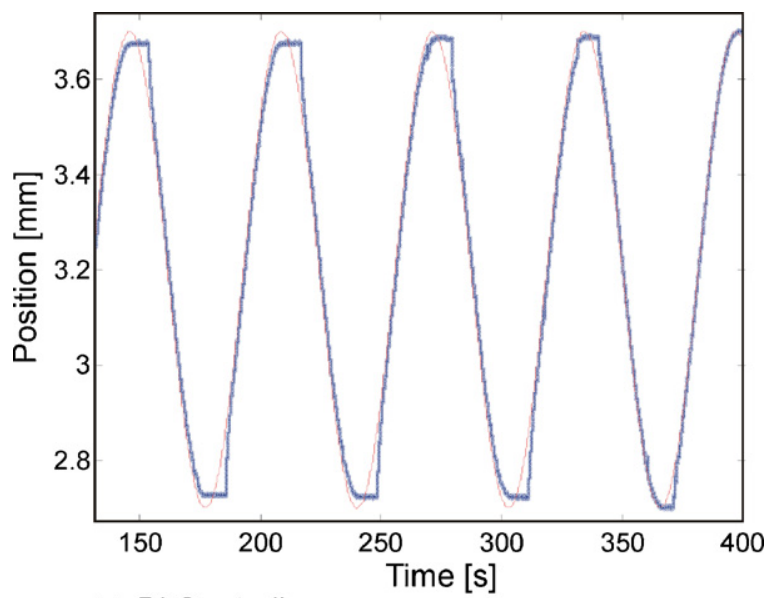

(a) PI Controller

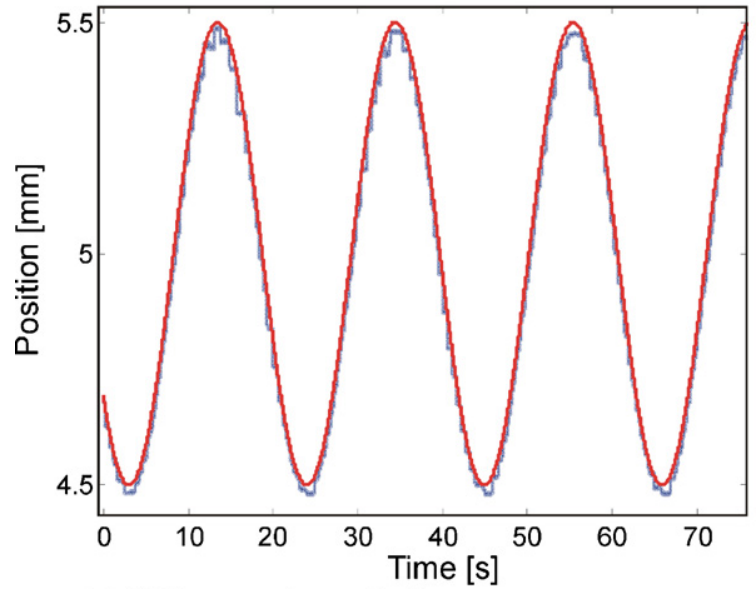

(b) Sliding mode controller

Fig. 14. Sinusoidal position tracking with a PI (top) and a sliding mode (bottom) controller.

total system. As can be seen in this figure, the actuator follows the desired position over the entire position range. The highest positioning error measured during this experiment is enlarged in the lower part of Fig. 13. The error is initially about $40 \mu \mathrm{m}$, but is corrected to approximately $12 \mu \mathrm{m}$ after $10 \mathrm{~s}$ by the control system. This relatively slow reaction is partially due to the pressure vessel (see Fig. 11). Similar experiments always showed position errors below 20-30 $\mu \mathrm{m}$.

When following for instance a sinusoidal signal, a relatively large tracking error is occurring at the locations where the position direction of the actuator is inverted, as illustrated in Fig. 14a. This error can be reduced by using a sliding mode controller [16]. Sliding mode controllers allow to reject external disturbing forces such as friction in this case, and have already been implemented successfully in large-scale pneumatic actuators [17]. The measurements shown in Fig. 14b show that in the case of our miniature actuator, the tracking error is reduced from 100 to $30 \mu \mathrm{m}$ by using a sliding mode controller. Outside the region where the actuator changes from actuation direction, there is no improvement in tracking accuracy when using a sliding mode controller.

Finally, the actuation speed of the actuator has been determined by differentiating the position signal. The maximum

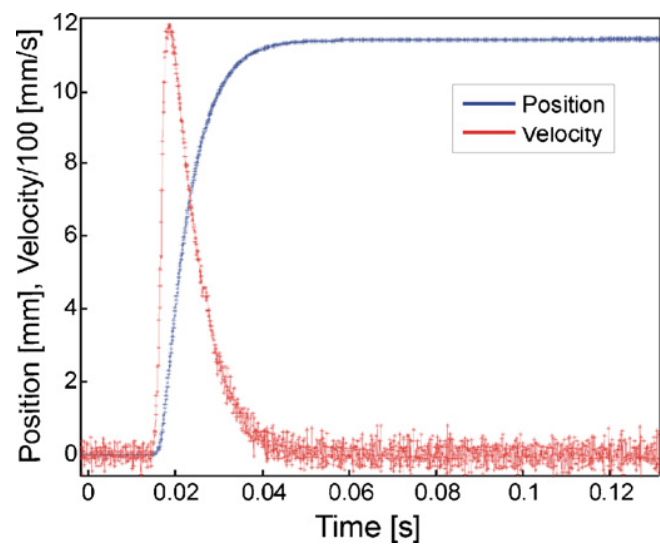

Fig. 15. Measurement of the actuation speed of the actuator.

actuation speed during the positioning tests was $70 \mathrm{~mm} / \mathrm{s}$. However, if the actuator is subjected to a sudden pressure step of $0.8 \mathrm{MPa}$, speeds up to $1200 \mathrm{~mm} / \mathrm{s}$ have repeatedly been observed as shown in Fig. 15. Usually the actuation speed of these actuators is limited by the pressure supply rather than by the actuator itself. Future research will investigate the control of the actuator by miniature valves as for instance presented in [18]

\section{Conclusions}

A compact pneumatic microactuator with an integrated position sensor has been fabricated and tested. The system has an outside diameter of $1.3 \mathrm{~mm}$, and a length of $15 \mathrm{~mm}$. The stroke of the actuator is $12 \mathrm{~mm}$, the actuation force is $1 \mathrm{~N}$ at $1.5 \mathrm{MPa}$ and the maximum actuation speed is more than $1 \mathrm{~m} / \mathrm{s}$. The position sensor allows to measure the position of the actuator with an accuracy of $\pm 10 \mu \mathrm{m}$ and the positioning accuracy of the actuator with a feed-back control loop is estimated to be $\pm 30 \mu \mathrm{m}$. The high force and power density of these actuators, and their accurate positioning capabilities makes them interesting for all robotic applications in which a high number of degrees of freedom need to be controlled in a restricted volume. Typical applications include inspection or assembly robots and tools for minimally invasive surgery.

\section{Acknowledgements}

This research is sponsored by the Institute for the Promotion of Innovation by Science and Technology in Flanders (IWT) and by the Interuniversity Attraction Pole "Advanced Mechatronic Systems". Finally, we would like to thank F. Ceyssens for the fabrication of SU8 seals.

\section{References}

[1] M. De Volder, J. Peirs, D. Reynaerts, J. Coosemans, B. Puers, O. Smal, B. Raucent, Production and characterization of a hydraulic microactuator, J. Micromech. Microeng. 15/7 (2005) S15-S21.

[2] M. De Volder, J. Peirs, D. Reynaerts, J. Coosemans, R. Puers, O. Smal, B. Raucent, A novel hydraulic microactuator sealed by surface tension, Sens. Actuators A 123-124 (2005) 547-554. 
[3] M. De Volder, F. Ceyssens, D. Reynaerts, R. Puers, A PDMS lipseal for hydraulic and pneumatic microactuators, J. Micromech. Microeng. 17 (2007) 1232-1237.

[4] S. Yokota, K. Kawamura, K. Takemura, K. Edamura, A high-integration micro-motor using electro-conjugated fluid (ECF), J. Robot. Mechatronics 17 (2005) 142-148.

[5] A.A. Norton, M.A. Minor, Pneumatic microactuator powered by the deflagration of sodium azide, J. Microelectromech. Syst. 15 (2006) 344-354.

[6] S. Wakimoto, K. Suzumori, T. Kanda, Development of intelligent McKibben actuator with built-in conductive rubber sensor, in: Proceedings of the Transducers 2005, 13th International Conference on Solid-State Sensors, Actuators and Microsystems, 2005, pp. 745-748.

[7] H. Zhu, W.J. Book, Construction and control of massive hydraulic microactuator-sensor Array, Proc. IEEE Intell. Control Symp. (2006) 820-825.

[8] J. Peirs, Design of micromechatronic systems: scale laws, technologies, and medical applications, Ph.D. Thesis, Leuven, 2001, ISBN 90-5682-247-0.

[9] H. Okayasu, J. Okamoto, M.G. Fujie, M. Umezu, H. Iseki, Development of a hydraulic-driven flexible manipulator for neurosurgery, Int. Congr. Ser. 1256 (2003) 607-612.

[10] C.D. Johnson, Process Control Instrumentation Technology, Prentice-Hall International, New Jersey, 2000.

[11] J.P. Bentley, Principles of Measurement Systems, Longman, Singapore, 1995.

[12] H. Sumali, E.P. Bystrom, G.W. Krutz, A displacement sensor for nonmetallic hydraulic cylinders, IEEE Sensors J. 3 (2003) 818-826.

[13] R.C. Johnson, H. Jasik, in: H. Jasik (Ed.), Antenna Engineering Handbook, McGraw-Hill, New York, 1984.

[14] V.G. Welsby, The Theory and Design of Inductance Coils, 2nd ed., Wiley, New York, 1960.

[15] R.C. Dorf, R.H. Bishop, Modern Control Systems, 8th ed., Addison-Wesley World Student Series, Menlo Park, 1998.

[16] C. Edwards, S.K. Spurgeon, Sliding Mode Control: Theory and Applications, Taylor and Francis, 1998.

[17] H.S. Choi, C.S. Han, K.Y. Lee, S.H. Lee, Development of hybrid robot for construction works with pneumatic actuator, Automation in Construction 14 (2005) 452-459.

[18] M. De Volder, K. Yoshida, S. Yokota, D. Reynaerts, The use of liquid crystals in microsystems: model and measurements, J. Micromech. Microeng. (2006) 612-619.

\section{Biographies}

Michael De Volder was born in Antwerp, Belgium, in 1978. He graduated as mechanical engineer at the University of Leuven (Belgium) in 2002. He afterwards started his $\mathrm{PhD}$ thesis at the Division of Production Engineering, Machine Design and Automation (PMA) of the same university. In 2005, he stayed as a visiting researcher at the Precision \& Intelligence Laboratory of the Tokyo Institute of Technology (Japan). In 2007, he obtained his PhD degree from the Faculty of Engineering Sciences of the University of Leuven. Currently, he is work- ing as a post doctoral researcher of the Fund for Scientific Research-Flanders (F.W.O.-Vlaanderen). His research interests include microactuators, hydraulic microdevices, and micro- and nanosystems in general.

Johan Coosemans was born in Wilrijk, Belgium, in 1978. He received his MS degree in microelectronics from the Katholieke Universiteit Leuven in 2001. In 2001, he joined the ESAT-MICAS laboratory at the K.U. Leuven as a research assistant of the Fund for Scientific Research-Flanders (Belgium) (F.W.O.-Vlaanderen). He is currently working towards a PhD. His main research interests are: pressure sensors, low power sensor interfaces, data acquisition systems for biomedical applications and biotelemetry.

Robert Puers was born in Antwerp, Belgium, 1953. He received his BS degree in electrical engineering in Ghent in 1974, and his MS degree at the Katholieke Universiteit Leuven in 1977, where he obtained his PhD in 1986.

From 1980, he was employed as a research assistant at the Laboratory ESAT at K.U. Leuven. In 1986, he became Director (NFWO) of the clean room facilities for silicon and hybrid circuit technology at the ESAT-MICAS laboratories of the same university. He was a pioneer in the European research efforts in silicon micromachined sensors, MEMS and packaging techniques, for biomedical implantable systems as well as for industrial devices. In addition, his general interest in low power telemetry systems, with the emphasis on low power intelligent interface circuits and on inductive power and communication links has promoted the research of the ESAT-MICAS laboratory to international recognition.

At present, he is as a full professor at the K.U. Leuven, teaching courses in 'Microsystems and Sensors', in 'Biomedical Instrumentation and Stimulation', in 'Production techniques for microelectronics', and a basic course in 'Electronics, System Control and Information Technology'. He is the author or co-author of more than 350 papers on biotelemetry, sensors, MEMS and packaging in reviewed journals or international conferences.

$\mathrm{He}$ is a fellow of the Institute of Physics (UK), council member of the International Microelectronics and Packaging Society (IMAPS), senior member of the Institute for Electrical and Electronical Engineers (IEEE) and many others.

He is Editor-in-Chief of the IOP Journal of Micromechanics and Microengineering, General Chairman of the Eurosensors conferences and General Program Chairman for Transducers'07 in Lyon.

Dominiek Reynaerts was born in Tienen, Belgium, in 1963. He received his mechanical engineering degree from the Katholieke Universiteit Leuven, Belgium, in 1986. He has been working at the Mechanical Engineering Department of that same university, as a research assistant, starting from $1986 . \mathrm{He}$ obtained his $\mathrm{PhD}$ degree in mechanical engineering in 1995 with the thesis "Control methods and actuation technology for whole-hand dexterous manipulation", and became assistant professor at the Katholieke Universiteit Leuven in 1997.

He currently is a professor in mechanical engineering with research and teaching activities in precision engineering, micro-mechanical systems, advanced actuators and design methodology. He is a member of IEEE and euspen. 